\title{
Sonic hedgehog carried by microparticles corrects endothelial injury through nitric oxide release
}

\author{
Abdelali Agouni, ${ }^{* 1}$ H. Ahmed Mostefai,*,1 Chiarra Porro,* Nunzia Carusio,* \\ Julie Favre, ${ }^{\dagger}$ Vincent Richard, ${ }^{\dagger}$ Daniel Henrion, ${ }^{*}$ M. Carmen Martínez, ${ }^{*}$ \\ and Ramaroson Andriantsitohaina*,2 \\ *INSERM, U771, CNRS, UMR 6214, Université d'Angers, Faculté de Médecine, Angers, France; \\ and 'INSERM, U644, Université de Rouen, UFR Médecine/Pharmacie, Rouen, France
}

\begin{abstract}
Microparticles (MPs) are small fragments generated from the plasma membrane after cell stimulation. Among the candidate proteins harbored by MPs, we recently showed that sonic hedgehog (Shh) is present in MPs generated from activated/apoptotic human T lymphocytes [Martínez et al., Blood (2006) vol. 108, 3012-3020]. We show here that Shh carried by MPs induces nitric oxide (NO) release from endothelial cells, triggers changes in the expression and phosphorylation of enzymes related to the NO pathway, and decreases production of reactive oxygen species. When PI3-kinase and ERK signaling were specifically inhibited, the effects of MPs were reversed. In vivo injection of MPs in mice was also able to improve endothelial function by increasing NO release, and it reversed endothelial dysfunction after ischemia/reperfusion. Silencing the effects of Shh with cyclopamine, a specific inhibitor of Shh, or siRNA, an inhibitor of the Shh receptor Patched, strongly reduced production of NO elicited by MPs. Taken together, we propose that the biological message carried by MPs harboring Shh may represent a new therapeutic approach against endothelial dysfunction during acute severe endothelial injury.-Agouni, A., Mostefai, H. A., Porro, C., Carusio, N., Favre, J., Richard, V., Henrion, D., Martínez, M. C., Andriantsitohaina, R. Sonic hedgehog carried by microparticles corrects endothelial injury through nitric oxide release. FASEB J. 21, 2735-2741 (2007)
\end{abstract}

Key Words: microvesicles $\cdot$ NO-synthase $\cdot M P s \cdot$ PI3-kinase inhibitor

AfTER CELl STimulation, A SignificAnt and sustained increase in cytosolic $\mathrm{Ca}^{2+}$ leads to the collapse of membrane phospholipid asymmetry by acting on pumps responsible for phospholipid transport. Changes in lipid distribution, mainly phosphatidylserine and cytoskeleton degradation by $\mathrm{Ca}^{2+}$-dependent proteases, are followed by microparticle (MPs) release (for a review, see ref. 1). MPs are small in size; their protein composition is not completely elucidated, but it differs in function from the cell origin and stimuli of their generation (2). Recent reports show that circulating MPs or those generated in vitro from apoptotic $\mathrm{T}$ cells display dele- terious effects on endothelial and/or vasomotor function $(3,4)$. Enhanced levels of circulating MPs have been detected in several cardiovascular and hematological pathologies (5-9), strengthening the notion that MPs may play a role in these diseases. Indeed, MPs can be regarded as vectors of biological messages such as induction of endothelial dysfunction, angiogenesis, or differentiation $(3,10,11)$.

Among the candidate proteins implicated in the ligand-receptor interactions between target cells and MPs, we have reported that the morphogen sonic hedgehog (Shh) is carried by MPs (11). Indeed, MPs generated from activated/apoptotic $\mathrm{T}$ cells or from plasma from diabetic patients harbor Shh and are able to induce differentiation and changes in the cell cycle of human K562 pluripotent erythroleukemic and primary CD34 cells (11). Shh is involved in embryonic and adult development (12), and dysregulation of the Shh pathway can lead to tumors (13) and erectile dysfunction (14). This latter effect is associated with a reduction of nitric oxide (NO) production by the corpora cavernosa. Indeed, NO-synthase (NOS) and vascular endothelial growth factor (VEGF) are downstream targets of exogenous Shh signaling, suggesting that Shh can act as a modulator of the regulation of VEGF and NO production (14). It was recently reported that intracellular elements of the Shh signal involve PI3kinase and Akt (15), which are also associated with NO production in endothelial cells (16).

Recent evidence shows that MPs are important for communication between cells. Among the actions of MPs, it has been described that they can transfer receptors and organelles between cells and deliver mRNA and proteins into cells (17). We consider here engineering human $\mathrm{T}$ lymphocytes undergoing activation/apoptosis in order to generate MPs bearing Shh, as described (11). We have examined the effects of this type of MP on endothelial function and dysfunction

\footnotetext{
${ }^{1}$ These authors contributed equally to this work.

${ }^{2}$ Correspondence: INSERM, U771, CNRS, UMR 6214, Université d'Angers, Faculté de Médecine, Rue Haute de Reculée, Angers, F-49045 France. E-mail: ramaroson.andriantsitohaina@ univ-angers.fr

doi: 10.1096/fj.07-8079com
} 
after an ischemia/reperfusion with respect to production $\mathrm{NO}$ and reactive species of oxygen (ROS).

\section{MATERIALS AND METHODS}

\section{MPs production}

The human lymphoid CEM T cell line (ATCC, Manassas, VA, USA) was used for MP production. Cells were seeded at $10^{6}$ cells $/ \mathrm{ml}$ and cultured in serum-free X-VIVO 15 medium (Cambrex, Walkersville, MD, USA). MPs were produced as described previously (11). Briefly, CEM cells were treated with phytohemagglutinin $(5 \mu \mathrm{g} / \mathrm{ml}$; Sigma, St. Louis, MO, USA) for $72 \mathrm{~h}$, then with phorbol-12-myristate-13 $(20 \mathrm{ng} / \mathrm{ml}$, Sigma) and actinomycin D $(0.5 \mu \mathrm{g} / \mathrm{ml}$, Sigma $)$ for $24 \mathrm{~h}$. A supernatant was obtained by centrifugation at $750 \mathrm{~g}$ for 15 min, then at $1500 \mathrm{~g}$ for $5 \mathrm{~min}$ to remove cells and large debris, respectively. MPs from the supernatant were washed after three centrifugation steps (45 min at 14,000 g) and recovered in $400 \mu \mathrm{l} \mathrm{NaCl}(0.9 \% \mathrm{w} / \mathrm{v})$. Washing medium for the last supernatant was used as control. Determination of the amount of MPs was carried out by measuring MP-associated proteins, using the method of Bradford (18), with BSA (Sigma) as the standard.

\section{Cell culture}

The Eahy 926 endothelial cell line was cultured in growth medium (DMEM, Ham's F-12, 1:1) supplemented with 1\% L-glutamine, $1 \%$ HAT, $1 \%$ NEAA, $1 \%$ Na-pyruvate, $1 \%$ streptomycin/penicillin (Cambrex), and 10\% FBS (Invitrogen, Cergy Pontoise, France). Cells were grown for $24 \mathrm{~h}$ in the absence or presence of $10 \mu \mathrm{g} / \mathrm{ml}$ MPs preincubated or not with inhibitors [PI3-kinase inhibitor LY294002, $20 \mu \mathrm{M}$ (Calbiochem, London, UK), MEK inhibitor U0126, $2 \mu \mathrm{M}$ (Calbiochem), NOS inhibitor nitro-L-arginine (L-NA), $100 \mu \mathrm{M}$ (Sigma), or cyclopamine $30 \mu \mathrm{M}$ (Sigma)].

\section{NO determination by electron paramagnetic resonance (EPR)}

Detection of NO production was performed using a technique with $\mathrm{Fe}^{2+}$ diethyldithiocarbamate (DETC, Sigma) as spin trap. Briefly, after $24 \mathrm{~h}$ of MP treatment, cells were stimulated with either vehicle or bradykinin (20 $\mu \mathrm{M}$, Sigma) for $45 \mathrm{~min}$ at $37^{\circ} \mathrm{C}$; medium was replaced with $250 \mu \mathrm{l}$ of Krebs solution, then treated with $250 \mu$ l of colloid Fe(DETC) 2 and incubated for $45 \mathrm{~min}$ at $37^{\circ} \mathrm{C}$. NO detection was measured in situ by EPR. Values are expressed in units $/ \mu \mathrm{g} / \mu \mathrm{l}$ of endothelial cell proteins.

In another set of experiments, animals received i.p. injections of DETC $(400 \mathrm{mg} / \mathrm{kg})$, followed by s.c. injection of ferrous citrate; animals were sacrificed $30 \mathrm{~min}$ later. Blood and tissues (lung and aorta) were dissected and immediately frozen in plastic tubes using liquid nitrogen. NO spin trapping and EPR studies were performed as described previously (4). Values are expressed in units/ $\mu$ l of blood or in units/mg weight of dried tissue (aorta and lung).

\section{Vascular reactivity}

All animal studies were carried out using approved institutional protocols. Male Swiss mice ( 8 to 10 wk old) were treated in vivo by i.v. injection into the tail vein of MPs (10 $\mu \mathrm{g} / \mathrm{ml}$ of blood) or the same volume of vehicle in the absence or presence of cyclopamine $(10 \mathrm{mg} / \mathrm{kg}$, i.p.). For studies in normal arteries, aortic rings were isolated $24 \mathrm{~h}$ after MPs were injected and mounted on a wire myograph filled with Krebs solution with the following composition in mM: $\mathrm{NaCl} 130$, $\mathrm{NaHCO}_{3}$ 14.9, KCl 3,7, $\mathrm{KH}_{2} \mathrm{PO}_{4} 1.2, \quad \mathrm{MgSO}_{4} \cdot 7 \mathrm{H}_{2} \mathrm{O}$ 1.2, $\mathrm{CaCl}_{2} \cdot \mathrm{H}_{2} \mathrm{O} 1.6$, glucose $11\left(37^{\circ} \mathrm{C}, 95 \% \mathrm{O}_{2}-5 \% \mathrm{CO}_{2}\right)$. Mechanical activity was recorded isometrically by a force transducer (Danish Myo Technology, Aarhus, Denmark) (4). Concentration-response curves were constructed by cumulative application to acetylcholine ( $1 \mathrm{nM}$ to $10 \mu \mathrm{M}$, Sigma) to vessels with functional endothelium precontracted with U46619 (30 nM, Sigma). For ischemia/reperfusion studies, mice were anesthetized and mechanically ventilated. A thoracotomy was performed and ischemia was induced by ligating the left anterior descending coronary artery proximal to its origin. After 30 min the suture was removed to permit reperfusion for $1 \mathrm{~h}$. Then the heart was removed and immediately placed in cold oxygenated Krebs solution $\left(37^{\circ} \mathrm{C}, 95 \% \mathrm{O}_{2}-5 \% \mathrm{CO}_{2}\right)$. A segment of the coronary artery ( 1.5 to $2 \mathrm{~mm}$ in length) distal to the site of occlusion was carefully dissected and mounted on a myograph. Endothelial function of a distal coronary artery was assessed on the basis of vascular studies performed earlier $(19,20)$. Concentration-response curves to acetylcholine (10 $\mathrm{nM}$ to $30 \mu \mathrm{M})$ were performed in serotonin-precontracted segments (10 $\mu \mathrm{M}$, Sigma).

\section{Dihydroethidine staining and flow cytometry}

After incubation of endothelial cells with MPs at $10 \mu \mathrm{g} / \mathrm{ml}$ for $24 \mathrm{~h}$ in the presence or absence of the PI3-K inhibitor (LY294002, $20 \mu \mathrm{M}$ ), the MEK inhibitor (U0126, $2 \mu \mathrm{M}$ ), or the NOS inhibitor (L-NA, $100 \mu \mathrm{M}$ ), cells were washed three times with PBS, then incubated with the oxidative fluorescent dye dihydroethidine (DHE, $3 \mu \mathrm{M}$, Sigma). Fluorescent-positive cells were determined by flow cytometry.

\section{Western blot}

After treatments, cells were homogenized and lysed. Proteins (20 $\mu \mathrm{g}$ ) were separated on 10\% SDS-PAGE. Blots were probed with anti-endothelial NOS (eNOS), caveolin-1 (BD Biosciences, San Jose, CA, USA), phospho-caveolin-1 Tyr 14, phospho-eNOS Ser-1177, phospho-eNOS Thr 495, phosphoP42/44 (Cell Signaling, Beverly, MA, USA), and Patched (Santa Cruz Biotechnology, Santa Cruz, CA, USA) antibodies. A polyclonal rabbit anti-human $\beta$-actin antibody (SigmaAldrich) was used at 1/5,000 dilution to visualize protein gel loading. The membranes were then washed at least three times in Tris buffer solution containing $0.05 \%$ Tween and incubated for $1 \mathrm{~h}$ at room temperature with the appropriate horseradish peroxidase (HRP)-conjugated secondary antibody (Amersham Biosciences, Piscataway, NJ, USA). The protein-antibody complexes were detected by ECL plus (Amersham) according to the protocol of the manufacturer.

\section{RNA interference and transient transfection}

To silence Patched, the Shh receptor, siRNA duplexes specific for human Patched and control, nonsilencing siRNA were obtained from Santa Cruz Biotechnology. Transient transfection of Eahy 926 endothelial cells was done according to the manufacturer's protocol. Briefly, cells were seeded in 6-well plates, grown for $24 \mathrm{~h}(60 \%$ confluence $)$, then transiently transfected with $100 \mathrm{nM}$ of Patched-specific or control siRNA using the transfection reagent provided, which also served as control without siRNA. Medium was replaced $24 \mathrm{~h}$ later by fresh medium and cells were grown for an additional $24 \mathrm{~h}$ before either Western blot analysis of Patched expression or functional studies. In another set of experiments, cells 
were treated with MPs and NO measurements were performed.

\section{Data analysis}

Data are represented as mean \pm SEM; $n$ represents the number of animals or experiments as appropriate. Statistical analyses were performed by 1-way analysis of variance (ANOVA), Student's $t$ test (parametric), Mann-Whitney U tests (nonparametric), or ANOVA for repeated measures with a subsequent Bonferroni post hoc test. $P<0.05$ was considered to be statistically significant.

\section{RESULTS}

MPs promote NO release and decrease ROS production

MPs induced an increase in NO production in human endothelial cells. This increase was observed in basal conditions and after stimulation with bradykinin (Fig. 1A). We investigated the pathways involved in MP-induced NO production. MPs induced an increase in eNOS expression and in its phosphorylation at Ser-1177 and Thr 495 (activator and inhibitor sites, respectively) (Fig. $1 B$ ), phosphorylation of the activator site being significantly higher than that of the inhibitor site (Fig. $1 G$ ), indicating activation of the NO production pathway. When the PI3-kinase pathway was antagonized specifically with LY294002, the effects of the MPs were reversed, suggesting that this cascade is involved in MP-induced NO production. We also found that MPs both decreased the expression of caveolin-1 and enhanced its phosphorylation; these effects were inhibited by the PI3-kinase inhibitor (Fig. 1D). However, not all of the effects of MPs on protein expression and phosphorylation were modified in the presence of the ERK inhibitor, U0126 (not shown). In addition, incubation with MPs reduced ROS production in endothelial cells. This effect was abolished in the presence of the inhibitors of PI3-kinase or ERK but was not affected by the NOS inhibitor, L-NA (Fig. 1E). Neither LY294002, U0126, nor L-NA alone had a significant effect on ROS as measured by flow cytometry ( $\%$ positive cells: $52 \pm 2$, $45 \pm 6,46 \pm 6,56 \pm 4$ for control, LY294002, U0126, or
A

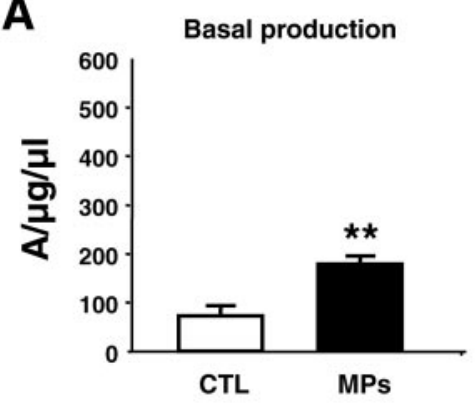

C

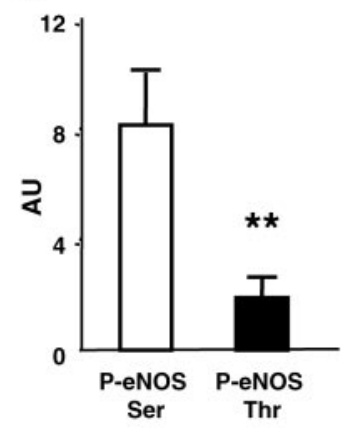

B
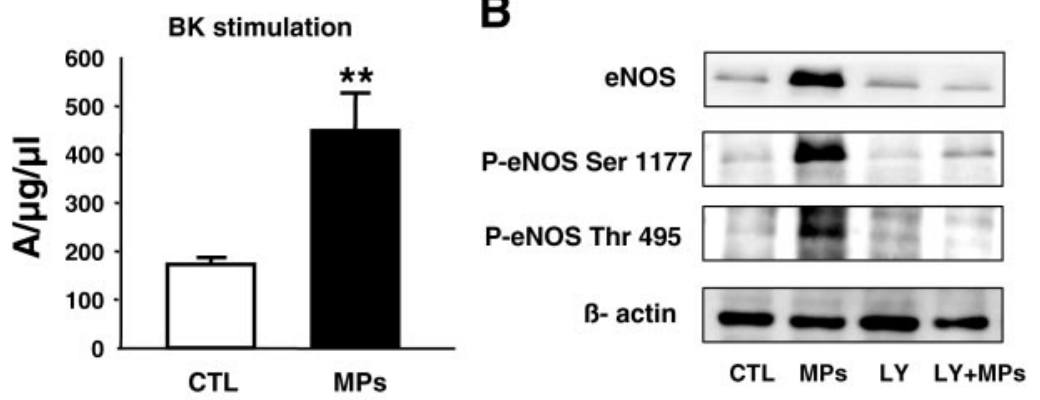

E

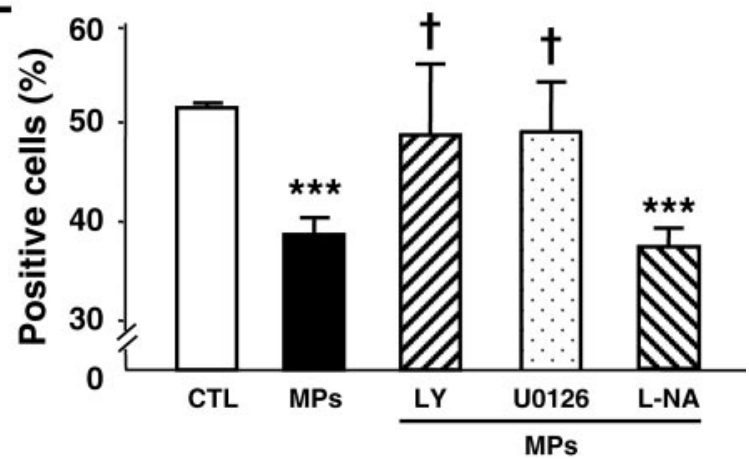

Figure 1. MPs promote NO-synthase (NOS) expression and activity and decrease ROS production. A) Quantification of the amplitude of the NO-Fe(DETC) $)_{2}$ complex signal in human Eahy endothelial cells. Cells were incubated in the absence (basal conditions) or presence of bradykinin (BK, $20 \mu \mathrm{M}$ ) for $45 \mathrm{~min}$. Values are expressed as units $/ \mu \mathrm{g} / \mu \mathrm{l}$ of protein in the samples $(n=5)(* * P<0.01) . B)$ Human Eahy endothelial cells were treated for $24 \mathrm{~h}$ with either medium (CTL) or $10 \mu \mathrm{g} / \mu \mathrm{l} \mathrm{MPs}$ in the absence or presence of the PI3-kinase inhibitor LY294002 (LY). Western blot revealed eNOS expression and phosphorylation of Ser-1177 (activator site) and of Thr 495 (inhibitory site) $(n=6)$. C) Quantification of the phosphorylation of the activator and the inhibitory site of eNOS $(* * P<0.01)$ (AU, arbitrary units). D) Human Eahy endothelial cells were treated for $24 \mathrm{~h}$ with either medium (CTL) or $10 \mu \mathrm{g} / \mu \mathrm{l}$ MPs in the absence or presence of the PI3-kinase inhibitor LY294002 (LY). Western blot revealed caveolin-1 expression and phosphorylation $(n=6)$. E) Human Eahy endothelial cells were treated for $24 \mathrm{~h}$ with either medium (CTL) or $10 \mu \mathrm{g} / \mu \mathrm{l} \mathrm{MPs} \mathrm{in} \mathrm{the} \mathrm{absence} \mathrm{or} \mathrm{presence} \mathrm{of} \mathrm{PI3-kinase} \mathrm{inhibitor} \mathrm{LY,} \mathrm{ERK1/2} \mathrm{inhibitor} \mathrm{U0126,} \mathrm{or} \mathrm{NOS} \mathrm{inhibitor} \mathrm{L-NA,}$ then stained with DHE and analyzed by flow cytometry $(n=5)(* * * P<0.001$ vs. control cells; $\uparrow P<0.05$ vs. cells treated with MPs alone). 
L-NA, respectively). As a positive control, lipopolysaccharide was used (not shown).

MPs enhance endothelium-dependent relaxation and restore endothelial dysfunction through NO release

To evaluate the in vivo physiological significance of MPs in NO production, MPs were injected into mice for $24 \mathrm{~h}$. Under these conditions, MPs enhanced the acetylcholineevoked endothelial relaxation of precontracted vessels (Fig. 2A). Blood, aorta, and lung from control or MPtreated mice exhibited a NO-Fe(DETC) $)_{2}$ signal that was greater in samples from mice treated with MPs than in those obtained from control mice (Fig. $2 B-D$ ). To determine whether this enhanced production of NO by MPs is also associated with protective effects against endothelial dysfunction, we assessed relaxation responses to acetylcholine in coronary arteries from mice subjected to 30 min ischemia (left coronary occlusion), followed by 60 min reperfusion (Fig. 2E). Ischemia/reperfusion (I/R) markedly reduced the coronary relaxation to acetylcholine; however, the endothelial dysfunction was entirely reversed after administration of MPs $24 \mathrm{~h}$ before ischemia, showing that MPs may preserve coronary endothelial integrity and functionality in severe acute endothelial injury.
Silencing Shh signaling neutralizes the effects of MPs

To determine whether Shh accounts for the effects evoked by MPs, we examined the effect of Shh inhibition on MP-induced NO production. Treatment of endothelial cells with either the selective Shh inhibitor, cyclopamine, or siRNA to the Shh receptor, Patched, resulted in a reduction of MPs' effects on NO production (Fig. 3A, B). In addition, pretreatment of mice with cyclopamine reversed the enhancement of endothelium-dependent relaxation evoked by MPs (Fig. 3C). Cyclopamine treatment reduced the amount of $\mathrm{NO}$ detected in blood, aorta, and lung from mice treated with MPs (Fig. 3D-F). Together, these findings suggest that the effects of MPs are directly mediated by the Shh cascade, as illustrated by endothelial dysfunction in the presence of the Shh pathway inhibitor.

\section{DISCUSSION}

The results of the present study clearly show that engineered MPs presenting membrane-bound Shh induce NO production from endothelial cells and tissues; this effect is mediated directly by the Shh pathway, as illustrated by the reduction of NO production when the Shh pathway was silenced. NO generated after in vivo
A

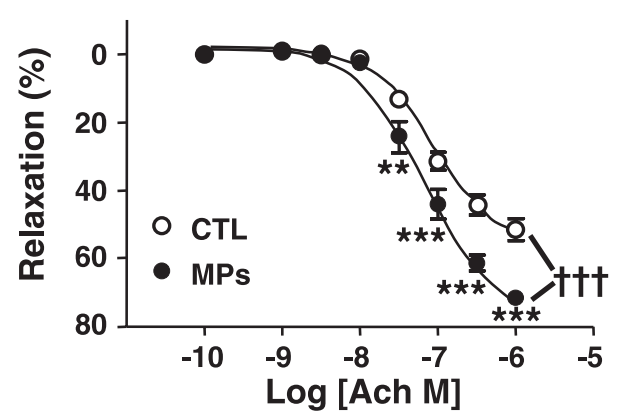

B

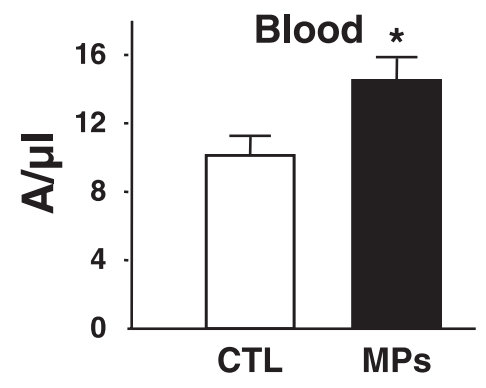

C

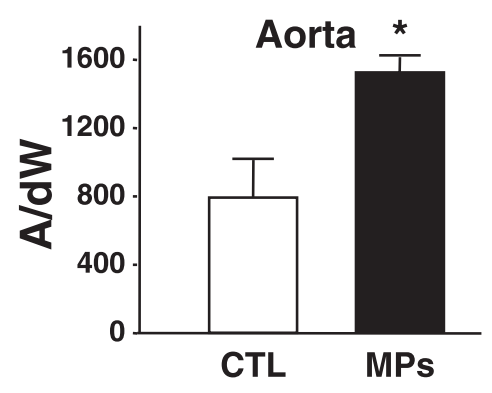

D

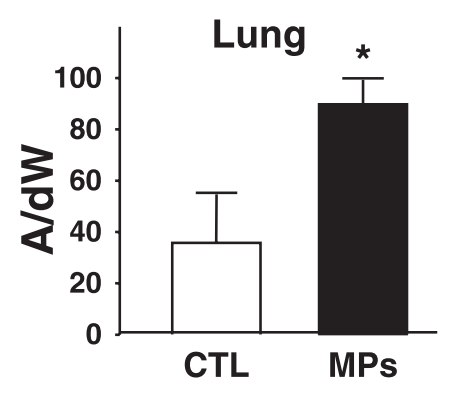

E

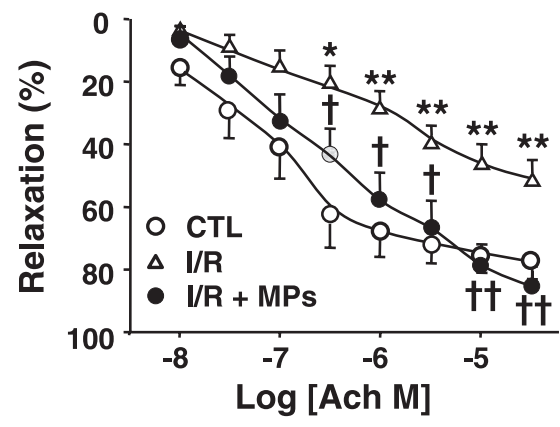

Figure 2. MPs improve endothelial function. A) Acetylcholine-induced relaxation in control (CTL) and MP-injected mouse aorta. Results were expressed as a percentage of relaxation of U46619-induced precontraction. ( $* * P<0.01, * * * P<0.001$ between each acetylcholine concentration; $\dagger+P<0.001$ between the two curves) $(n=6)$. B-D) Quantification of the amplitude of the $\mathrm{NO}-\mathrm{Fe}(\mathrm{DETC})_{2}$ complex signal in circulating blood $(B)$, aorta $(C)$, and lung $(D)$ from either control (CTL) or in vivo MP-treated mice. Values are expressed in units $/ \mu$ l blood $(n=6)$ or in units $/ \mathrm{mg}$ weight of dried lung or aorta $(n=6)(* P<0.05)$. $E)$ Acetylcholine-induced relaxation in control (CTL) and MP-injected mouse coronary arteries after cardiac ischemia/reperfusion $(\mathrm{I} / \mathrm{R})(n=5)(* P<0.05, * * P<0.01 \mathrm{I} / \mathrm{R}$ vs. control; $\uparrow P<0.05, \dagger \dagger P<0.01 \mathrm{I} / \mathrm{R}+\mathrm{MPs}$ vs. I/R $)$. 

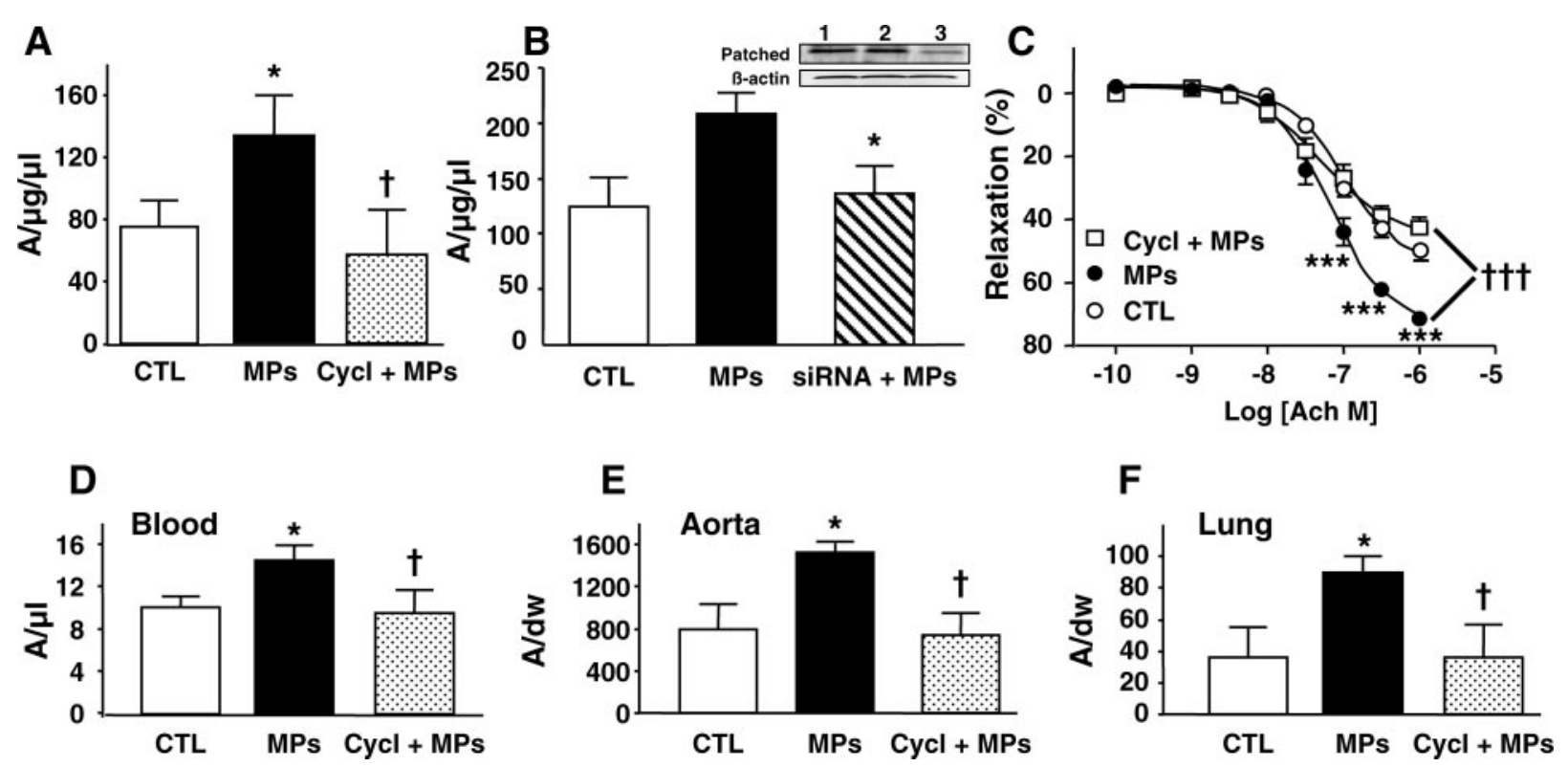

Figure 3. The Shh pathway accounts for the effects induced by MPs. A, B) Quantification of the amplitude of the NO-Fe(DETC) 2 complex signal in either control (CTL), MP-, cyclopamine $(\operatorname{cycl}, 30 \mu \mathrm{M})+\mathrm{MP}-(A)$, or siRNA of the Shh receptor Patched $(B)$ -treated human Eahy endothelial cells $(* P<0.05)(n=5)$. Insert shows Western blot for Patched in the control $($ lane 1$)$, siRNA scrambled-(lane 2), or Patched siRNA (lane 3) -treated Eahy endothelial cells. $C$ ) Acetylcholine-induced relaxation in control (CTL), MP-, and MPs + cycl-injected mouse aortic rings $(n=6) \quad(* * * P<0.001$ between each acetylcholine concentration; $\dagger+P<0.001$ between curves). $D-F)$ Quantification of the amplitude of the NO-Fe(DETC) ${ }_{2}$ complex signal in circulating blood, aorta, and lung from in vivo $\mathrm{cycl}+\mathrm{MP}$-treated mice $(n=6)$. Values are expressed as in Fig. $2(* P<0.05$ vs. control; $\uparrow P<0.05$ vs. the presence of MPs alone).

MP treatment enhances endothelium-dependent relaxation in normal mice but also restores endothelial dysfunction in coronary arteries subjected to ischemia/ reperfusion.

The concentration of MPs used here is in the range of those able to promote differentiation of megakaryocytes (11), suggesting that low concentrations of MPs harboring Shh can induce important effects on the cardiovascular system. In addition, the effects evoked by MPs were dependent on the stimuli used for their generation, as suggested by others (21). Indeed, MPs from apoptotic actinomycin D-treated $\mathrm{T}$ cells did not produce NO release from endothelial cells (A. H. Mostefai and R. Andriantsitohaina, unpublished results) probably due to the absence of Shh in these MPs (11).

MPs used in the present study induce both the increase of NO release and the decrease in ROS production, with the latter being independent of the former as shown by the absence of effect of the NOS inhibitor. The concomitant effect of $\mathrm{NO}$ and ROS production might result in an enhancement of the bioavailability of generated $\mathrm{NO}$ by reducing oxidative stress and the subsequent scavenging of NO. The increase in NO release was associated with an enhancement of eNOS expression and activity, as reflected by the increase in eNOS phosphorylation, and with changes in the expression and phosphorylation of caveolin-1. All of these effects of MPs on pathways involved in NO production, except on caveolin-1 expression, were dependent on the PI3-kinase pathway. By contrast, the reduction in ROS induced by MPs was dependent on PI3-kinase and ERK pathways, as observed in other models (22). Altogether, these results indicate that MPs are able to modulate eNOS expression and activity and reduce oxidative stress in human endothelial cells, leading to a beneficial potential effect on the cardiovascular system.

The generation of NO induced by MPs was corroborated after in vivo injection of MPs into mice. MPs were able to enhance endothelial NO relaxation to acetylcholine, which was accompanied by an increase of NO production in tissues and blood. MPs restore endothelial dysfunction after ischemia/reperfusion. It has been accepted that ischemia/dysfunction evoke deleterious consequences at the level of the myocardium and the coronary artery. The endothelial dysfunction described under these conditions is characterized by impaired endothelium-dependent vasodilatation, an exaggerated endothelium-dependent vasoconstriction, and increased production of endothelin-1 and ROS, leading to increased vasoconstriction and reduction of blood flow; the endothelium then becomes dysfunctional and NO formation decreases (23). In the present study, MPs restore endothelial injury probably through their dual ability to increase NO and reduce ROS.

We recently demonstrated that MPs generated from activated/apoptotic T cells carried Shh, a morphogen essential for embryonic development and other functions in the adult. Indeed, Shh signaling participates in the normal and diseased pancreas, hematopoietic differentiation, or erectile dysfunction $(14,24-27)$. With regard to the latter, injection in the corpora cavernosa of exogenous Shh protein 
induces eNOS and VEGF. These results suggest that Shh may prevent the reduction of NO production in erectile dysfunction and highlight the clinical relevance of the Shh pathway for treatment of impotence (14). The Shh receptor Patched is normally expressed in cardiovascular tissues (25). In the present study, all the effects induced by MP treatment were inhibited when the Shh pathway was silenced by cyclopamine or by siRNA against the Shh receptor, indicating that Shh bound to MPs directly produces $\mathrm{NO}$ release from endothelial cells. PI3-kinase and Akt belong to the intracellular pathway for endothelial NO release. Here we show that MPs bearing Shh enhance both eNOS expression and activity via mechanisms sensitive to the PI3-kinase inhibitor. In conjunction with these studies, it has been reported that PI3-kinase and Akt are essential for Shh signaling $(15,28)$. Altogether, one can advance the hypothesis that Shh harboring by MPs cause NO release via PI3-kinase and Akt pathways.

To our knowledge, this is the first study to demonstrate that engineered MPs from human activated/ apoptotic $\mathrm{T}$ lymphocytes carrying Shh improve endothelial function and prevent endothelial dysfunction via NO release. It was recently reported that Shh gene therapy may have considerable therapeutic potential by improving cardiac function in either ischemia or infarct models and wound healing in diabetes $(29,30)$. Here we propose that generation of MPs harboring Shh from $\mathrm{T}$ cells and the biological message they carried may represent a new therapeutic approach, independent of gene therapy, with which to correct cardiovascular pathologies linked to endothelial dysfunction. FJ

We thank Dr. R. Hiley for careful reading of the manuscript. This work was supported by institutional grants from Fondation pour la Recherche Médicale (no. INE20050303433 and no. INE20060306500), Fonds Européen pour le Développement Régional (no. 8891), CNRS, INSERM et Université d'Angers. A.A. and H.A.M. are recipients of a doctoral fellowship from French Education Ministry and Conseil Régional du Pays de la Loire, respectively.

\section{REFERENGES}

1. Hugel, B., Martínez, M. C., Kunzelmann, C., and Freyssinet J.-M. (2005) Membrane microparticles: two sides on the coin. Physiology 20, 22-27

2. Martínez, M. C., Tesse, A., Zobairi, F., and Andriantsitohaina, R. (2005) Shed membrane microparticles from circulating and vascular cells in regulating vascular function. Am. J. Physiol. 288, H1004-H1009

3. Martin, S., Tesse, A., Hugel, B., Martínez, M. C., Morel, O. Freyssinet, J.-M., and Andriantsitohaina, R. (2004) Shed membrane particles from $\mathrm{T}$ lymphocytes impair endothelial function and regulate endothelial protein expression. Circulation 109, $1653-1659$

4. Tesse, A., Martínez, M. C., Hugel, B., Chalupsky, K., Muller, C. D., Meziani, F., Mitolo-Chieppa, D., Freyssinet, J.-M., and Andriantsitohaina, R. (2005) Upregulation of proinflammatory proteins through NF-кB pathway by shed microparticles results in vascular hyporeactivity. Arterioscler. Thromb. Vasc. Biol. 25, 2522-2527
5. Mallat, Z., Benamer, H., Hugel, B., Benessiano, J., Steg, P. G., Freyssinet, J.-M., and Tedgui, A. (2000) Elevated levels of shed membrane microparticles with procoagulant potential in the peripheral circulating blood of patients with acute coronary syndromes. Circulation 101, 841-843

6. Sabatier, F., Darmon, P., Hugel, B., Combes, V., Sanmarco, M., Velut, J. G., Arnoux, D., Charpiot, P., Freyssinet, J.-M., Oliver, C., et al. (2002) Type 1 and type 2 diabetic patients display different patterns of cellular microparticles. Diabetes 51, 2840-2845

7. Jimenez, J. J., Jy, W., Mauro, L. M., Horstman, L. L., Soderland, C., and Ahn, Y. S. (2003) Endothelial microparticles released in thrombotic thrombocytopenic purpura express von Willebrand factor and markers of endothelial activation. Br. J. Haematol. 123, 896-902

8. Barry, O. P., Pratico, D., Savani, R. C., and Fitzgerald, G. A. (1998) Modulation of monocytes-endothelial cell interactions by platelet microparticles. J. Clin. Invest. 102, 136-144

9. Nomura, S., Tandon, N. N., Nakamura, T., Cone, J., Fukuhara, S., and Kambayashi, J. (2001) High-shear-stress-induced activation of platelets and microparticles enhances expression of cell adhesion molecules in THP-1 and endothelial cells. Atherosclerosis 158, 277-287

10. Mezentsev, A., Merks, R. M., O'Riordan, E., Chen, J., Mendelev, N., Goligorsky, M. S., and Brodsky, S. V. (2005) Endothelial microparticles affect angiogenesis in vitro: role of oxidative stress. Am. J. Physiol. 289, H1106-H1114

11. Martínez, M. C., Larbret, F., Zobairi, F., Coulombe, J., Debili, N. Vainchenker, W., Ruat, M., and Freyssinet, J.-M. (2006) Transfer of differentiation signal by membrane microvesicles harbouring hedgehog morphogens. Blood 108, 3012-3020

12. Ingham, P. W., and McMahon, A. P. (2001) Hedgehog signalling in animal development: paradigms and principles. Genes Dev. 15, 3059-3087

13. Pasca di Magliano, M., and Hebrok, M. (2003) Hedgehog signalling in cancer formation and maintenance. Nat. Rev. Cancer 3, 903-911

14. Podlasek, C. A., Meroz, C. L., Korolis, H., Tang, Y., McKenna, K. E., and McVary, K. T. (2005) Sonic hedgehog, the penis and erectile dysfunction: a review of sonic hedgehog signalling in the penis. Curr. Pharm. Des. 11, 4011-4027

15. Riobó, N.A., Lu, K., Ai, X., Haines, G. M., and Emerson, C. P., Jr. (2006) Phosphoinositide 3-kinase and Akt are essential for sonic hedgehog signaling. J. Biol. Chem. 103, 4505-4510

16. Shiojima, I., and Walsh, K. (2003) Role of Akt signaling in vascular homeostasis and angiogenesis. Circ. Res. 90, 1243-1250

17. Ratajczak, J., Wysoczynski, M., Hayek, F., Janowska-Wieczorek, A., and Ratajczak, M. Z. (2006) Membrane-derived microvesicles: important and underappreciated mediators of cellto-cell communication. Leukemia 20, 1487-1495

18. Bradford, M. (1976) A rapid and sensitive method for the quantitation of microgram quantities of protein utilizing the principle of protein-dye binding. Anal. Biochem. 72, 248-254

19. Richard, V., Kaeffer, N., Tron, C., and Thuillez, C. (1994) Ischemic preconditioning protects against coronary endothelial dysfunction induced by ischemia and reperfusion. Circulation 89, 1254-1261

20. Kaeffer, N., Richard, V., and Thuillez, C. (1997) Delayed coronary endothelial protection 24 hours after preconditioning. Role of free radicals. Circulation 96, 2311-2316

21. Baj-Krzyworzeka, M., Majka, M., Pratico, D., Ratajczak, J., Vilaire, G., Kijowski, J., Reca, R., Janowska-Wieczorek, A., and Ratajczak, M. Z. (2002) Platelet-derived microparticles stimulate proliferation, survival, adhesion, and chemotaxis of hematopoietic cells. Exp. Hematol. 30, 450-459

22. Yang, H. Y., Kim, J., Chung, G. H., Lee, J. C., and Jang, Y. S. (2007) Cross-linking of MHC class II molecules interferes with phorbol 12,13-dibutyrate-induced differentiation of resting $B$ cells by inhibiting Rac-associated ROS-dependent ERK/p38 MAP kinase pathways leading to NF-kappaB activation. Mol. Immunol. 44, 1588-1597

23. Moens, A. L., Claeys, M. J., Timmermans, J. P., and Vrints, C. J. (2005) Myocardial ischemia/reperfusion-injury, a clinical view on a complex pathophysiological process. Int. J. Cardiol. 100, $179-190$

24. Kayed, H., Kleeff, J., Osman, T., Keleg, S., Buchler, M. W., and Friess, H. (2006) Hedgehog signaling in the normal and diseased pancreas. Pancreas 32, 119-129 
25. Pola, R., Ling, L. E., Silver, M., Corbley, M. J., Kearney, M., Pepinsky, R. B., Shapiro, R., Taylor, F. R., Baker, D. P., Asahara, T., and Isner, J. M. (2001) The morphogen sonic hedgehog is an indirect angiogenic agent upregulating two families of angiogenic growth factors. Nat. Med. 7, 706-711

26. Vokes, S. A., Yatskievych, T. A., Heimark, R. L., McMahon, J., McMahon, A. P., Antin, P. B., and Krieg, P. A. (2004) Hedgehog signaling is essential for endothelial tube formation during vasculogenesis. Development 131, 4371-4380

27. Bhardwaj, G., Murdoch, B., Wu, D., Baker, D. P., Williams, K. P., Chadwick, K., Ling, L. E., Karanu, F. N., and Bhatia, M. (2001) Sonic hedgehog induces the proliferation of primitive human hematopoietic cells via BMP regulation. Nat. Immunol. 2, 172180

28. Kanda, S., Mochizuki, Y., Suematsu, T., Miyata, Y., Nomata, K., and Kanetake, H. (2003) Sonic hedgehog induces capillary morphogenesis by endothelial cells through phosphoinositide 3-kinase. J. Biol. Chem. 278, 8244-8249

29. Kusano, K. F., Pola, R., Murayama, T., Curry, C., Kawamoto, A., Iwakura, A., Shintani, S., Ii, M., Asai, J., Tkebuchava, T., et al. (2005) Sonic hedgehog myocardial gene therapy: tissue repair through transient reconstitution of embryonic signaling. Nature Med. 11, 1197-1204

30. Asai, J., Takenaka, H., Kusano, K. F., Ii, M., Luedemann, C., Curry, C., Eaton, E., Iwakura, A., Tsutsumi, Y., Hamada, H., et al. (2006) Topical sonic hedgehog gene therapy accelerates wound healing in diabetes by enhancing endothelial progenitor cell-mediated microvascular remodeling. Circulation 113, 2413-2424

Received for publication January 10, 2007. Accepted for publication March 8, 2007. 